\title{
Characterizing forest fragmentation: distinguishing change in composition from configuration
}

\author{
Jed A. Long ${ }^{\mathrm{a}}$, Trisalyn A. Nelson ${ }^{\mathrm{a}}$, Michael A. Wulder ${ }^{\mathrm{b}}$ \\ ${ }^{a}$ Spatial Pattern Analysis \& Research (SPAR) Laboratory, Dept of Geography, \\ University of Victoria, PO Box 3060, Victoria, BC, V8W 3R4, Canada. \\ ${ }^{\mathrm{b}}$ Canadian Forest Service (Pacific Forestry Centre), Natural Resources Canada, 506 West \\ Burnside Road, Victoria, BC, V8Z 1M5, Canada. \\ *corresponding author: \\ Jed A. Long, email: jlong@uvic.ca, phone: (250) 853 - 3271
}

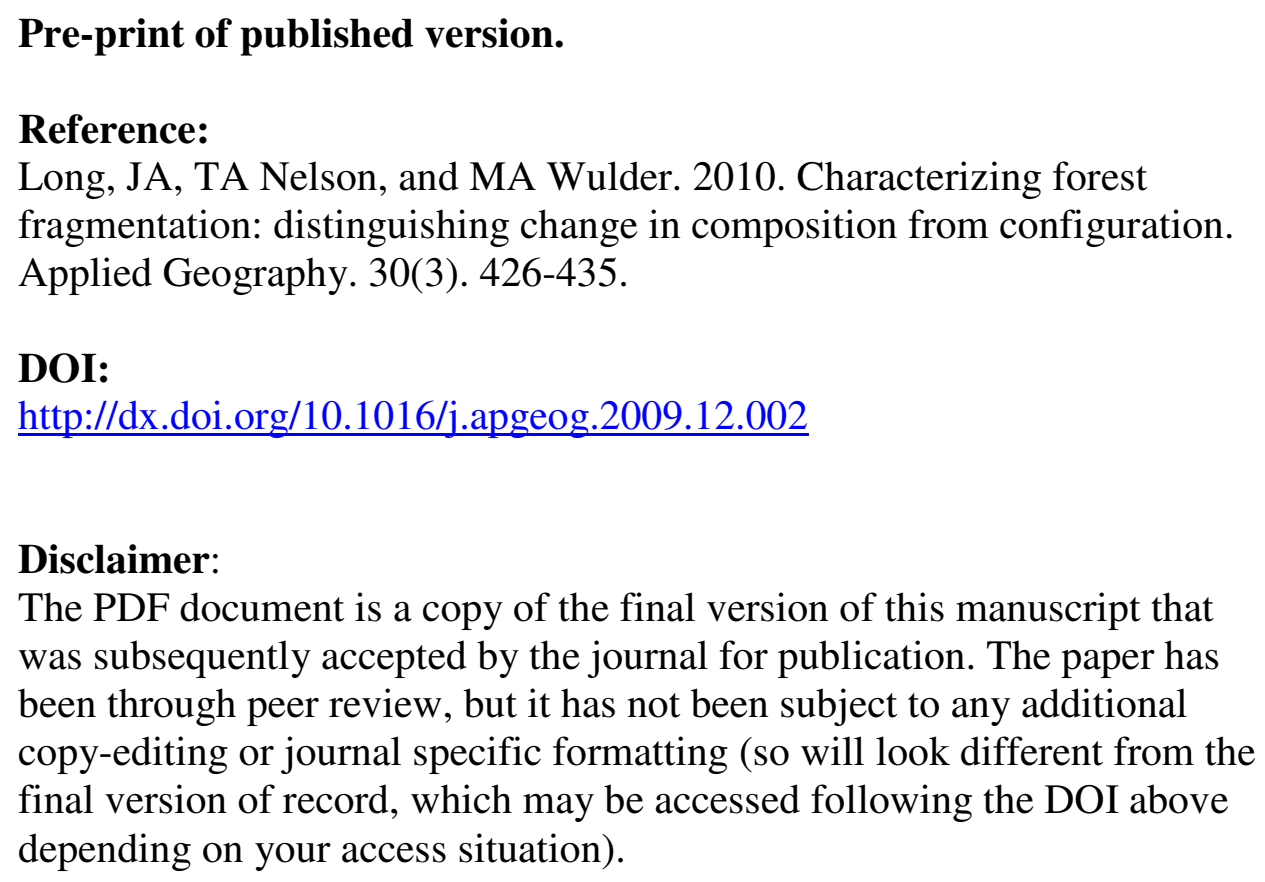

\section{Disclaimer:}

The PDF document is a copy of the final version of this manuscript that was subsequently accepted by the journal for publication. The paper has been through peer review, but it has not been subject to any additional copy-editing or journal specific formatting (so will look different from the final version of record, which may be accessed following the DOI above depending on your access situation).

Key Words: Forest loss; Mountain pine beetle; Landscape displacement; Trajectory analysis; Spatial pattern; Landscape change 


\begin{abstract}
Forest fragmentation can generally be considered as two components: 1) compositional change representing forest loss, and 2) configurational change or change in the arrangement of forest land cover. Forest loss and configurational change occur simultaneously, resulting in difficulties isolating the impacts of each component. Measures of forest fragmentation typically consider forest loss and configurational change together. The ecological responses to forest loss and configurational change are different, thus motivating the creation of measures capable of isolating these separate components. In this research, we develop and demonstrate a measure, the proportion of landscape displacement from configuration $\left(P_{y}\right)$, to quantify the relative contributions of forest loss and configurational change to forest fragmentation. Landscapes with statistically significant forest loss or configurational change are identified using neutral landscape simulations to generate underlying distributions for $P_{y}$. The new measure, $P_{y}$, is applied to a forest landscape where substantial forest loss has occurred from mountain pine beetle mitigation and salvage harvesting. The percent of forest cover and six LPIs (edge density, number of forest patches, area of largest forest patch, mean perimeter area ratio, corrected mean perimeter area ratio, and aggregation index) are used to quantify forest fragmentation and change. In our study area, significant forest loss occurs more frequently than significant configurational change. The $P_{y}$ method we demonstrate is effective at identifying landscapes undergoing significant forest loss, significant configurational change, or experiencing a combination of both loss and configurational change.
\end{abstract}

\title{
1 - Introduction
}

Forest loss and change in the configuration of forest land cover are often considered collectively as fragmentation. Forest loss and fragmentation are known to impact wildlife survival, habitat quality (Fahrig, 1997), and an organism's ability to navigate the landscape (Schumaker, 1996). However, species respond differently forest loss and configurational change (Fahrig, 1997). Studies aimed at quantifying the effects of forest fragmentation frequently employ landscape pattern indices (LPIs) to measure forest loss (compositional change) and change in the arrangement (configurational change) of forest on the landscape.

Tracking changes in raw LPI values over time is frequently used to monitor forest fragmentation (e.g., Frohn and Hao, 2006); however, the comparison of raw LPI values is problematic due to interdependencies between the composition of the landscape and resulting configuration values (Gustafson and Parker, 1992; Hargis et al., 1998). Current research suggests that comparison of raw LPI values should be avoided (Gergel, 2007), and new methods for comparing LPI values (e.g., Remmel and Csillag, 2003) or maps of land cover (e.g., Csillag et al., 2006; Remmel and Csillag, 2006) may be useful for adding statistical context to landscape pattern analysis.

The continuing use of LPIs is a testament to their broad applicability (Cardille and Turner, 2002), ease of implementation (McGarigal and Marks, 1995; Mladenoff and DeZonia, 2004), and computational simplicity (McGarigal and Marks, 1995). Forest fragmentation studies frequently employ LPIs as a means of quantitative analysis of landscape change (e.g., Gillanders et al., 2008; Nagendra et al., 2006; Serra et al., 2008), however a statistical framework is generally absent (Csillag and Boots, 2005). 
Statistically significant change in fragmentation is difficult to identify with a single measure because of the interdependency between the amount forest loss and resulting change in configuration LPIs. In order to properly identify significant landscape change composition must be considered in the context of configuration to account for the dependency of configurational change on forest loss.

To illustrate the importance of considering both composition and configuration when characterizing forest fragmentation consider the following example. Edge density (ED) is a common metric used to characterize forest fragmentation. In binary simulated landscapes ED has been shown to have the relationship portrayed in Figure 1, with edge density values peaking when the proportion of forest is $50 \%$. If a landscape that is predominantly forest (T1 in Figure 1) were to undergo small (T2a in Figure 1), or large (T2b in Figure 1), amounts of forest loss, two markedly different landscapes would result. Similar values for the configuration metric ED and similar changes in ED would be expected in both scenarios. The problem of identical LPI values is common to many LPIs frequently used in fragmentation studies and can be clearly seen using simulated landscapes (Figure 2). In real landscapes (taken from our study area) increased variability in LPI is observed and the problem identical LPI at multiple composition levels is more apparent (Figure 2 insets).

$<<$ Approximate location Figure 1 $>>$

$<<$ Approximate location Figure $2>>$

Trajectory analysis of LPI values, introduced by Cushman \& McGarigal (2007), provides a useful framework for quantifying temporal trends in landscape pattern. Cushman \& McGarigal identify four metrics for describing the trajectory of a landscape (displacement, velocity, acceleration, and divergence). We build upon the displacement measure, which characterizes the distance between the location of a landscape and its starting point in LPI attribute space. Displacement can be used to measure the magnitude of change a landscape has incurred, but does not describe the nature of this change. Based on displacement, we develop an approach for quantifying forest fragmentation that separately identifies landscapes undergoing significant forest loss or configurational change.

The objective of this research is to introduce a method for quantifying forest fragmentation by isolating the separate processes of forest loss and configurational change using LPIs. We introduce a metric: $P_{y}$, the proportion of landscape displacement from configuration, which identifies significant changes as either forest loss or configurational change. An application using a region in British Columbia, Canada, which has been subject to mountain pine beetle (Dendroctonus ponderosae) infestation, and subsequent salvage and mitigation harvest activities is used to highlight this approach. Over this region we demonstrate how the $P_{y}$ approach improves interpretation of fragmentation measured with LPIs by identifying landscapes that have simply experienced forest loss or more complex configurational change.

\section{2 - Material and Methods}

2.1 - An Approach for Characterizing Forest Fragmentation

2.1.1 - Displacement $\left(D_{i}\right)$ 
Displacement $\left(D_{i}\right)$, is computed by measuring the distance between T1 and T2 LPI values on a two-dimensional plane where the $\mathrm{x}$-axis is composition, and the $\mathrm{y}$-axis is a configuration LPI [1].

$$
D_{i}=\sqrt{d_{x}^{2}+d_{y}^{2}}
$$

$D_{i}$ is the displacement of the landscape for configuration index $i$, and $d_{x}$ is the change in composition between the two time periods, and $d_{y}$ is the change in configuration index $i$. $D_{i}$ is used to measure the magnitude of overall change, but is also used for the derivation of $P_{y} . D_{i}$ calculated in this manner, exclusively considers change in a configuration LPI with change in composition, as has been recommended (Gergel, 2007; Remmel and Csillag, 2003).

2.1.2 - Proportion of Displacement from Configuration $\left(P_{y}\right)$

From [1] the following relationship exists:

$$
D_{i}^{2}=d_{x}^{2}+d_{y}^{2}
$$

Based upon this understanding, we define the proportion of the displacement from configuration $\left(P_{y}\right)[3]$, which ranges from $0-1$ :

$$
P_{y}=\frac{d_{y}^{2}}{D_{i}^{2}}
$$

$P_{y}$ measures the relative amount of configurational change given the overall displacement (including change in forest amount). Low $P_{y}$ values indicate change due primarily to forest loss, high $P_{y}$ values indicate change due primarily to configurational change, and medium $P_{y}$ values indicate both forest loss and configurational change have occurred.

\section{2 - Study Area}

Located within the interior plateau of British Columbia, Canada, the Prince George forest district (Figure 3) is situated primarily in the Sub-Boreal Spruce biogeoclimatic zone (Meidinger and Pojar, 1991). White spruce (Picea glauca), subalpine fir (Abies lasiocarpa), and lodgepole pine (Pinus contorta) are the dominant forest species within this region. The Prince George forest district has experienced extensive timber losses due to mountain pine beetle infestation, and an increased annual allowable cut was prescribed as a salvage and spread mitigation strategy (British Columbia Ministry of Forests and Range, 2007). A $40 \mathrm{~km}$ by $40 \mathrm{~km}$ study area that was subject to infestation by mountain pine beetle and related management activities is the basis of our case study.

\section{3 - Data}

$$
<<\text { Approximate location Figure } 3>>
$$

A land cover dataset for 2000 was obtained from the Earth Observation for Sustainable Development of forests (EOSD) program (Wulder et al., 2003; Wulder et al., 2008a). These data, derived from Landsat-7 ETM+ imagery with land cover products resampled to a spatial resolution of $25 \mathrm{~m}$, represent an applicable spatial resolution for monitoring forest disturbance (Healey et al., 2007). The EOSD data consist of 23 detailed land cover classes that are developed through a logical hierarchy that enables aggregation into three base generalized land cover classes: forest, non-forest and other (see Wulder and Nelson, 2003) to support the generation of LPI. To monitor forest loss and fragmentation, an analogous year 2006 forest, non-forest, other classification was generated from Landsat imagery. The enhanced wetness difference index (EWDI) change detection method (Franklin et al., 2001; Franklin et al., 2002) was used to derive a binary 
forest change map for 2006 following Han et al. (2007). The 2000 EOSD data were updated to 2006 conditions, converting the forest class to non-forest where forest loss was detected based on the EWDI method. An independent 2006 land cover classification was not created thereby avoiding error propagation related to the comparison of separate land cover classifications representing different dates (Fuller et al., 2003).

The validity of the 2000 land cover dataset created under the EOSD program has been assessed in three separate studies (Remmel et al., 2005; Wulder et al., 2006; Wulder et al., 2007). Over all applicable EOSD classes (e.g., 23 class generalization to cover types) a target accuracy of over $80 \%$ was obtained using the mode class of a $3 \times 3$ spatial neighbourhood of the EOSD data (Wulder et al., 2007), which contains more detail than was used in this study. Accuracy was found to increase as class generalization is undertaken (Remmel et al., 2005). We performed an accuracy assessment on the 2006 land cover dataset. Visual interpretation of $0.5 \mathrm{~m}$ digital imagery was used as validation data based upon an existing framework used in the EOSD program (Wulder et al., 2007). An overall accuracy of $91.3 \%$ was obtained, with high user $(100 \%)$ and producer $(87.5 \%)$ accuracies for the forest class.

\section{4 - Analysis}

\subsection{1 - Selection of LPIS}

Six LPI (Table 1); edge density (ED), number of forest patches (NPF), area of largest forest patch (FMAX), mean landscape perimeter area ratio (PAR), corrected mean landscape perimeter area ratio (CPAR), and aggregation index for the forest class (AI), were selected based on principles of forest fragmentation (Haines-Young and Chopping, 1996) and to provide examples of LPIs with varying relationships between composition and configuration (see Figure 2). Two analysis scales (landscapes) were chosen: $1 \mathrm{~km}$ ( $n$ $=1600)$ and $10 \mathrm{~km}(n=16)$ non-overlapping square units. The 1 and $10 \mathrm{~km}$ analysis units represent typical scales used for examining landscape trends at the regional level (Wulder et al., 2008b).

\subsection{2 - Standardization of LPI Values}

$<<$ Approximate location Table $1>>$

When comparing multiple LPIs it is advantageous to standardize (normalize) values due to differences in measuring units and scale. LPI values were standardized to zero mean and unit variance using [4], outlined in Kaufman and Rousseeuw (1990).

$$
z_{k i}=\frac{x_{k i}-m_{i}}{s_{i}}
$$

Here, $z_{k i}$ is the standardized LPI value for observation $k$ of LPI $i, x_{k i}$ is the original LPI value for observation $k$ of LPI $i, m_{i}$ is the mean of LPI $i$, and $s_{i}$ is a measure of dispersion for LPI $i$. We use the mean absolute deviation as the measure of dispersion as it is more robust than the typically used standard deviation (Kaufman and Rousseeuw, 1990).

\subsection{3 - Identifying High and Low $P_{y}$ Values}

In order to identify high $P_{y}$ values, which indicate the dominance of configurational change, and low $P_{y}$ values, which indicate the dominance of forest loss, thresholds for defining high and low $P_{y}$ must be determined. Neutral (random) landscape simulations provide a logical starting point for generating distributions of $P_{y}$ to assist in delineating high and low $P_{y}$ values. Alternatively, distributions for $P_{y}$ could be generated using a large database of real landscapes that have undergone change. Landscape simulation has previously been used with LPIs to examine topics such as the relationship 
between landscape composition and configuration (Gustafson and Parker, 1992), statistically compare LPI values (Remmel and Csillag, 2003), and to develop spatially local measures (Boots, 2006).

We simulated 9999 random binary landscapes (coded 1,0) to represent forest/non-forest conditions. The T1 composition of each simulated landscape was drawn from a frequency distribution of landscape composition levels observed in our study area (where landscape composition was conditioned to be $>5 \%$ forest). The amount of loss was simulated by randomly drawing from the frequency distribution of observed forest loss in our study area (forest loss was conditioned to be $>0 \%$ ). The drawn amount of loss was then randomly removed from each simulated landscape to generate $9999 \mathrm{~T} 2$ landscapes of forest change. This simulation procedure is analogous to the changedetection method used for creating the real T1 and T2 forest/non-forest data. This procedure was repeated for both $1 \mathrm{~km}(40 \mathrm{x} 40$ pixel) and $10 \mathrm{~km}(400 \mathrm{x} 400$ pixel) analysis units.

Simulated T1 and T2 landscapes were used to generate distributions of $P_{y}$ for each configuration LPI. The randomly generated distribution of $P_{y}$ values can be used to identify statistically unexpected high or low $P_{y}$ values. Based on percentiles from random distributions of $P_{y}$, thresholds to define unexpectedly high or low $P_{y}$ are defined using a two-tailed test and $\alpha=0.10$.

\section{3 - Results}

\section{1 -Distributions of $\boldsymbol{P}_{\boldsymbol{y}}$ and selection of threshold values}

Distributions for $P_{y}$ from random simulated landscapes were used to derive threshold values for denoting significant $P_{y}$ results. Distributions for the 9999 random landscapes for the $1 \mathrm{~km}$ analysis unit are presented (Figure 4), along with the distributions of $P_{y}$ for the real landscapes at the $1 \mathrm{~km}$ scale (insets, Figure 4). The distributions for $P_{y}$ for the $10 \mathrm{~km}$ analysis unit are not given, but are comparable to those for the $1 \mathrm{~km}$ case. The distributions of $P_{y}$ show obvious peaks at $P_{y}=0$, except with the metric AI. $P_{y}=0$ represents landscapes where forest loss has occurred but no configurational change has been measured. Landscapes where $P_{y}=0$ are frequently associated with small levels of change. As we are using $P_{y}$ in an exploratory role, we separated $P_{y}=0$ into a unique class and derive thresholds for significant high and low $P_{y}$ from the distribution with these cases removed. Thus, four classes are reported: $P_{y}=0$, significant low $P_{y}$, significant high $P_{y}$, and not significant. $<<$ Approximate location Figure $4>>$

A liberal $\alpha$ value $(\alpha=0.10)$ was chosen for illustrative purposes. Values in the upper $5 \%$ of the distribution are denoted as significant high $P_{y}$ and those in the lower 5\% of the distribution are denoted as significant low $P_{y}$. The threshold values for $\alpha=0.10$ along with threshold values for $\alpha=0.05$ and $\alpha=0.20$ are given, to show the impact of this parameter (Table 2) for both the $1 \mathrm{~km}$ and $10 \mathrm{~km}$ analysis scales. Across scales of analysis, significant thresholds for $P_{y}$ do not differ greatly.

\section{2 $P_{y}$ results}

$<$ Approximate location Table $2>>$

Results for $P_{y}$ are reported for each of the six selected LPI at the $1 \mathrm{~km}$ (Figure 5) and $10 \mathrm{~km}$ (Figure 6) analysis scales. At the $1 \mathrm{~km}$ scale it is interesting to compare the number of significant results for different LPI. 1231 out of $16001 \mathrm{~km}$ analysis units 
experienced change. AI had the largest number of significant results, and FMAX the lowest (Table 3).

$$
\begin{aligned}
& <\text { Approximate location Figure } 5>> \\
& <<\text { Approximate location Figure } 6>> \\
& <<\text { Approximate location Table } 3>>
\end{aligned}
$$

Areas where $P_{y}$ is significantly high in all or most of the selected metrics are associated with configurational change (Figure 7). Areas where $P_{y}=0$ or $P_{y}$ is significantly low in all or most of the selected metrics indicate areas simply experiencing forest loss (Figure 7). Areas where $P_{y}$ is predominantly not significant are interpreted to be undergoing a combination of forest loss and configurational change.

$<$ Approximate location Figure $7>>$

\section{4 - Discussion}

Empirical studies have demonstrated explicit links between wildlife occurrence and forest fragmentation (e.g., habitat uptake by American marten, Hargis et al., 1999). Increasingly, conservation research relies on implicitly defined relationships between wildlife processes and fragmentation (e.g., whether an organism is positively or negatively impacted by fragmentation). Current international forest management policy now requires reporting on forest fragmentation, as it is considered an indicator of biological diversity (Montreal Process Liaison Office, 2000). The desire to use forest cover and pattern information as a quantitative indicator of forest biodiversity originates from a lack of consensus on ideal indicator species and the cost effectiveness of remote sensing methods (Noss, 1999). Single time LPI measurements have been used for initial reporting (Riitters et al., 2004; Wulder et al., 2008b), but effective methods for monitoring the temporal changes in forest loss and fragmentation, such as $P_{y}$, are required to evaluate forest management practices and change.

Research has shown that the environmental response to habitat loss and fragmentation are different (Fahrig, 1997). Forest loss can lead to reduced species diversity (Hill and Curran, 2001), while configurational changes have been linked to increased wildlife-vehicle collisions (Gonser et al., 2009). Separating the components of loss and configurational change is difficult given that, in general, configurational change is driven by some form of habitat (e.g., forest) loss. This has led researchers to explore the use of density (composition) based indicators for monitoring forest fragmentation (e.g., Wickham et al., 2008). However, these indicators are insensitive to properties related to configurational change (e.g., increased edge and number of patches, decreasing patch areas and connectivity). Distinct configurational changes resulting from deforestation imply different landscape altering processes, not detectable by simply monitoring forest loss (Mertens and Lambin, 1997). Using the mountain pine beetle case study, we demonstrate the ability of the metric $P_{y}$ to differentiate between landscapes primarily experiencing forest loss $\left(P_{y}=0\right.$ and significantly low $\left.P_{y}\right)$, concurrent forest loss and configurational change ( $P_{y}$ not significant), and those primarily experiencing configurational change (significantly high $P_{y}$ ).

Landscape simulation was used to generate distributions for $P_{y}$ for six LPI at two analysis scales. For five of the six LPI the distribution from 9999 simulated landscapes was comparable to the observed distribution (see Figure 4). For the AI metric however, the simulated distribution of $P_{y}$ was noticeably different from the observed distribution. It 
is likely that the randomization approach used for selecting thresholds is inappropriate for use with $\mathrm{AI}$ as the distribution in the real case was markedly different from the simulated landscapes.

Using a large database of changed landscapes at multiple scales, or simulating spatial aggregation in the randomization procedure (see Remmel and Csillag, 2003), could improve significance threshold selection. For example, use of the AI metric here was limited due to the extreme differences in the distribution of $P_{y}$ in the real and random scenarios. If the selection of significant $P_{y}$ was based on a more realistic distribution for the metric AI, significant results would be less frequent and have more relevance.

This research implemented two analysis scales $(1 \mathrm{~km}$ and $10 \mathrm{~km})$ suitable for regional monitoring of forest loss and fragmentation. Using the selected data grain (25 $\mathrm{m}$ ), analysis units smaller then $1 \mathrm{~km}$ tend towards forest patch or no patch, while those larger then $10 \mathrm{~km}$ offer reduced interpretability due to various landscape altering processes occurring simultaneously within the analysis unit (e.g., road creation and forest harvest). The size of the analysis unit impacts resulting values and interpretation of $P_{y}$. The discrepancy in results shown originates from a common problem in spatial analysis methods known as the modifiable areal unit problem (MAUP) (Jelinski and Wu, 1996; Openshaw, 1984). LPIs are well known to be impacted by the MAUP through choices of data grain and analysis unit (Lausch and Herzog, 2002; Wu, 2004) and as it is derived from LPIs, $P_{y}$ is too impacted by the MAUP. Their currently exists no solution to the MAUP, however a multi-scale approach is warranted when implementing $P_{y}$ to improve interpretation of results and limit scale related bias.

\section{5 - Conclusions}

Testing for significance with $P_{y}$ is appropriate using neutral landscapes when the relationship between configuration and composition (e.g., Figure 2) of real landscapes is similar to simulated landscapes. When this is not the case, such as with the AI metric, $P_{y}$ results are less useful. Our example focused on six LPIs, and we tried to select those with unique distributional properties (see Figure 2). Future work should explore $P_{y}$ with other LPIs to further examine its usefulness. In the interim, $P_{y}$ can still be a useful measure of change enabling hypothesis testing against an expectation of random change.

As land cover datasets increase in availability, methods that extract relevant information from categorical data are required. LPIs are useful in characterizing land cover patterns, and methods that improve temporal comparisons of LPIs are necessary. $P_{y}$ is successful at distinguishing landscapes impacted by forest loss and/or configurational change. Density based indicators of forest fragmentation may be appropriate in landscapes where $P_{y}$ is small; however, are limited in capturing important configurational changes. In a mountain pine beetle case study we demonstrate the ability of $P_{y}$ to identify landscapes suffering primarily from forest loss and those experiencing more complex configurational change. Raw LPI values are difficult to interpret when substantial forest loss has occurred (e.g., with salvage harvesting). The $P_{y}$ approach is able to identify those regions that have undergone significant forest loss which will have different ecological consequences from those undergoing significant configurational change.

\section{6 - Acknowledgements}


This project was funded by the Government of Canada through the Mountain Pine Beetle Program, a three-year, $\$ 100$ million program administered by Natural Resources Canada, Canadian Forest Service. Additional information on the Mountain Pine Beetle Program may be found at: http://mpb.cfs.nrcan.gc.ca. Chris Butson and Xiaoping Yuan of the British Columbia Ministry of Forests and Range and Joanne White of the Canadian Forest Service are thanked for insight and access to data critical to the success of this research. Thanks to Dennis Jelinski, an anonymous reviewer, and the editor for helpful comments greatly improving this manuscript.

\section{7 - References}

Boots, B. (2006). Local configuration measures for categorical spatial data: binary regular lattices. Journal of Geographical Systems, 8, 1-24.

British Columbia Ministry of Forests and Range (2007). Timber supply and the mountain pine beetle infestation in British Columbia: 2007 update. British Columbia Ministry of Forests and Range, Forest Analysis and Inventory Branch, Victoria, BC. 38p.

Cardille, J. and Turner, M. G. (2002). Understanding Landscape Metrics I. In: S. E. Gergel and M. G. Turner (Eds.) Learning Landscape Ecology: A Practical Guide to Concepts and Techniques. Springer-Verlag, New York, NY, pp. 85-111.

Csillag, F. and Boots, B. (2005). A framework for statistical inferential decisions in spatial pattern analysis. The Canadian Geographer, 49(2), 172-179.

Csillag, F., Kabos, S. and Remmel, T. K. (2006). Confidence in coincidence. International Journal of Remote Sensing, 27(6), 1269-1276.

Cushman, S. A. and McGarigal, K. (2007). Multivariate landscape trajectory analysis: An example using simulation modeling of American marten habitat change under four timber harvest scenarios. In: J. A. Bissonette and I. Storch (Eds.) Temporal Dimensions in Landscape Ecology: Wildlife Responses to Variable Resources. Springer US, pp. 119-140.

Fahrig, L. (1997). Relative effects of habitat loss and fragmentation on population extinction. The Journal of Wildlife Management, 61(3), 603-610.

Franklin, S. E., Lavigne, M. B., Moskal, L. M., Wulder, M. A. and McCaffrey, T. M. (2001). Interpretation of forest harvest conditions in New Brunswick using Landsat TM enhanced wetness difference imagery (EWDI). Canadian Journal of Remote Sensing, 27(2), 118-128.

Franklin, S. E., Lavigne, M. B., Wulder, M. A. and McCaffrey, T. M. (2002). Large-area forest structure change detection: An example. Canadian Journal of Remote Sensing, 28(4), 588-592.

Frohn, R. C. and Hao, Y. (2006). Landscape metric performance in analyzing two decades of deforestation in the Amazon Basin of Rondonia, Brazil. Remote Sensing of Environment, 100, 237-251.

Fuller, R. M., Smith, G. M. and Devereux, B. J. (2003). The characterisation and measurement of land cover change through remote sensing: problems in operational applications? International Journal of Applied Earth Observation and Geoinformation, 4, 243-253. 
Gergel, S. E. (2007). New directions in landscape pattern analysis and linkages with remote sensing. In: M. A. Wulder and S. E. Franklin (Eds.) Understanding Forest Disturbance and Spatial Pattern: Remote Sensing and GIS Approaches. Taylor \& Francis Group, Boca Raton, FL, pp. 173-208.

Gillanders, S. N., Coops, N. C., Wulder, M. A., Gergel, S. E. and Nelson, T. (2008). Multitemporal remote sensing of landscape dynamics and pattern change: describing natural and anthropogenic trends. Progress in Physical Geography, 32(5), 503-528.

Gonser, R. A., Jensen, R. R. and Wolf, S. E. (2009). The spatial ecology of deer-vehicle collisions. Applied Geography, 29(4), 527-532.

Gustafson, E. J. and Parker, G. R. (1992). Relationships between landcover proportion and indices of landscape spatial pattern. Landscape Ecology, 7, 101-110.

Haines-Young, R. and Chopping, M. (1996). Quantifying landscape structure: a review of landscape indices and their application to forested landscapes. Progress in Physical Geography, 20(4), 418-445.

Han, T., Wulder, M. A., White, J. C., Coops, N. C., Alvarez, M. F. and Butson, C. (2007). An efficient protocol to process Landsat images for change detection with tasselled cap transformation. IEEE Geoscience and Remote Sensing Letters, 4(1), 147-151.

Hargis, C. D., Bissonette, J. A. and David, J. L. (1998). The behaviour of landscape metrics commonly used in the study of habitat fragmentation. Landscape Ecology, 13, 167-186.

Hargis, C. D., Bissonette, J. A. and Turner, D. L. (1999). The influence of forest fragmentation and landscape pattern on American martens. Journal of Applied Ecology, 36, 157-172.

Healey, S. P., Cohen, W. B., Yang, Z. and Kennedy, R. E. (2007). Remotely sensed data in the mapping of forest harvest patterns. In: M. A. Wulder and S. E. Franklin (Eds.) Understanding Forest Disturbance and Spatial Pattern: Remote Sensing and GIS Approaches. Taylor \& Francis Group, Boca Raton, FL, pp. 63-84.

Hill, J. L. and Curran, P. J. (2001). Species composition in fragmented forests: conservation implications of changing forest area. Applied Geography, 21(2), 157-174.

Jelinski, D. E. and Wu, J. (1996). The modifiable areal unit problem and implications for landscape ecology. Landscape Ecology, 11(3), 129-140.

Kaufman, L. and Rousseeuw, P. J. (1990). Finding Groups in Data. John Wiley \& Sons, New York.

Lausch, A. and Herzog, F. (2002). Applicability of landscape metrics for the monitoring of landscape change: issues of scale, resolution and interpretability. Ecological Indicators, 2, 3-15.

McGarigal, K. and Marks, B. J. (1995). FRAGSTATS: Spatial pattern analysis program for quantifying landscape structure. General Technical Report PNW-GTR-351. USDA, Forest Service, Pacific, Northwest Research Station, Portland, OR.

Meidinger, D. and Pojar, J. eds. (1991). Ecosystems of British Columbia. Research Branch British Columbia Ministry of Forests. Special Report Series Vol. 06., Victoria, B.C. 
Mertens, B. and Lambin, E. F. (1997). Spatial modelling of deforestation in southern Cameroon. Applied Geography, 17(2), 143-162.

Mladenoff, D. J. and DeZonia, B. (2004). APACK 2.23 Analysis Software User's Guide. (Version 4-13-04).

Montreal Process Liaison Office (2000). Montreal process year 2000 progress report: Progress and innovation in implementing criteria and indicators for the conservation and sustainable management of temperate and boreal forests. The Montreal Process Liaison Office, Canadian Forest Service, Ottawa, Canada.

Nagendra, H., Pareeth, S. and Ghate, R. (2006). People within parks - forest villages, land-cover change and landscape fragmentation in the Tadoba Andhari Tiger Reserve, India. Applied Geography, 26(2), 96-112.

Noss, R. F. (1999). Assessing and monitoring forest biodiversity: A suggested framework and indicators. Forest Ecology and Management, 115, 135-146.

Openshaw, S. (1984). The Modifiable Areal Unit Problem. GeoBooks, Norwich, England.

Remmel, T. K. and Csillag, F. (2003). When are two landscape pattern indices significantly different? Journal of Geographical Systems, 5, 331-351.

Remmel, T. K. and Csillag, F. (2006). Mutual information spectra for comparing categorical maps. International Journal of Remote Sensing, 27(7), 1425-1452.

Remmel, T. K., Csillag, F., Mitchell, S. W. and Wulder, M. A. (2005). Integration of forest inventory and satellite imagery: a Canadian status assessment and research issues. Forest Ecology and Management, 207, 405-428.

Riitters, K. H., Wickham, J. D. and Coulston, J. W. (2004). A preliminary assessment of Montreal Process indicators of forest fragmentation for the United States. Environmental Monitoring and Assessment, 91, 257-276.

Schumaker, N. H. (1996). Using landscape indices to predict habitat connectivity. Ecology, 77(4), 1210-1225.

Serra, P., Pons, X. and Sauri, D. (2008). Land-cover and land-use change in a Mediterranean landscape: A spatial analysis of driving forces integrating biophysical and human factors. Applied Geography, 28(3), 189-209.

Wickham, J. D., Riitters, K. H., Wade, T. G. and Homer, C. (2008). Temporal change in fragmentation of continental US forests. Landscape Ecology, 23, 891-898.

Wu, J. (2004). Effects of changing scale on landscape pattern analysis: scaling relations. Landscape Ecology, 19, 125-138.

Wulder, M. A., Dechka, J. A., Gillis, M. D., Luther, J. E., Hall, R. J., Beaudoin, A. and Franklin, S. E. (2003). Operational mapping of the land cover of the forested area of Canada with Landsat data: EOSD land cover program. The Forestry Chronicle, 79(6), 1075-1083.

Wulder, M. A. and Nelson, T. (2003). EOSD land cover classification legend report: Version 2. Natural Resources Canada, Canadian Forest Service, Pacific Forestry Centre, Victoria, BC. 81p.

Wulder, M. A., White, J. C., Cranny, M., Hall, R. J., Luther, J. E., Beaudoin, A., Goodenough, D. G. and Dechka, J. A. (2008). Monitoring Canada's forests - Part 1: Completion of the EOSD land cover project. Canadian Journal of Remote Sensing, 34(6), 549-562. 
Wulder, M. A., White, J. C., Han, T., Coops, N. C., Cardille, J., Holland, T. and Grills, D. (2008). Monitoring Canada's forests - Part 2: National forest fragmentation and pattern. Canadian Journal of Remote Sensing, 34(6), 563-584.

Wulder, M. A., White, J. C., Luther, J. E., Strickland, G., Remmel, T. K. and Mitchell, S. W. (2006). Use of vector polygons for the accuracy assessment of pixel-based land cover maps. Canadian Journal of Remote Sensing, 32(3), 268-279.

Wulder, M. A., White, J. C., Magnussen, S. and McDonald, S. (2007). Validation of a large area land cover product using purpose-acquired airborne video. Remote Sensing of Environment, 106, 480-491. 
Table 1: Six selected LPIs and their formulation. LPIs were calculated using APACK version 2.23 (see Mladenoff and DeZonia, 2004).

\begin{tabular}{|c|c|c|}
\hline LPI & Formulation & Notes \\
\hline $\begin{array}{l}\text { Edge density } \\
(E D)\end{array}$ & $E D=\frac{P}{A}$ & \multirow{6}{*}{$\begin{array}{l}P=\text { total perimeter } \\
A=\text { landscape area } \\
n=\text { number of patches } \\
f=\text { forest patch } \\
a=\text { area of patch } \\
p=\text { perimeter of patch } \\
e_{f f}=\text { adjacent edges of class } f \text { and itself }\end{array}$} \\
\hline $\begin{array}{l}\text { Number of forest patches } \\
(N P F)\end{array}$ & $N P F=n_{f}$ & \\
\hline $\begin{array}{l}\text { Area of largest forest } \\
\text { patch }(F M A X)\end{array}$ & $F M A X=\max \left[a_{f}\right]$ & \\
\hline $\begin{array}{l}\text { Mean landscape perimeter } \\
\text { area ratio }(P A R)\end{array}$ & $P A R=\frac{\left(\sum_{j=1}^{n} \frac{p_{j}}{a_{j}}\right)}{n}$ & \\
\hline $\begin{array}{l}\text { Corrected mean landscape } \\
\text { perimeter area ratio } \\
(C P A R)\end{array}$ & $C P A R=\frac{\left(\sum_{j=1}^{n} \frac{p_{j}}{\sqrt{4 \pi a_{j}}}\right.}{n}$ & \\
\hline $\begin{array}{l}\text { Aggregation index forest } \\
\text { class }(A I)\end{array}$ & $A I=\frac{e_{f f}}{\max \left[e_{f f}\right]}$ & \\
\hline
\end{tabular}


Table 2: Comparison of threshold values for denoting significant $P_{y}$ using $\alpha=0.05,0.10$, and 0.20 , for $1 \mathrm{~km}$ (top) and $10 \mathrm{~km}$ (bottom) analysis units. Note: $\alpha=0.10$ was used in this study.

\begin{tabular}{|c|c|c|c|c|c|c|}
\hline \multirow{2}{*}{1 km } & \multicolumn{2}{|c|}{$\alpha=0.05$} & \multicolumn{2}{|c|}{$\alpha=0.10$} & \multicolumn{2}{|c|}{$\alpha=0.20$} \\
\hline & low & high & low & high & low & high \\
\hline ED & 0.0064 & 0.9254 & 0.0218 & 0.9165 & 0.0811 & 0.8997 \\
\hline NPF & 0.0012 & 0.9629 & 0.0026 & 0.9386 & 0.0076 & 0.9044 \\
\hline FMAX & 0.0016 & 0.8815 & 0.0094 & 0.8104 & 0.0854 & 0.7059 \\
\hline PAR & 0.0073 & 0.9790 & 0.0290 & 0.9550 & 0.1103 & 0.9118 \\
\hline CPAR & 0.0145 & 0.9752 & 0.0498 & 0.9521 & 0.1692 & 0.9063 \\
\hline AI & 0.2915 & 0.7248 & 0.3747 & 0.6390 & 0.4322 & 0.5685 \\
\hline \multirow{2}{*}{$10 \mathrm{~km}$} & \multicolumn{2}{|c|}{$\alpha=0.05$} & \multicolumn{2}{|c|}{$\alpha=0.10$} & \multicolumn{2}{|c|}{$\alpha=0.20$} \\
\hline & low & high & low & high & low & high \\
\hline ED & 0.0019 & 0.8678 & 0.0090 & 0.8612 & 0.0331 & 0.8447 \\
\hline NPF & 0.0003 & 0.9713 & 0.0005 & 0.9499 & 0.0010 & 0.9276 \\
\hline FMAX & 0.0111 & 0.8985 & 0.0397 & 0.8919 & 0.1265 & 0.8817 \\
\hline PAR & 0.0048 & 0.9268 & 0.0188 & 0.9145 & 0.0690 & 0.8872 \\
\hline CPAR & 0.1344 & 0.9401 & 0.3206 & 0.9287 & 0.3210 & 0.8953 \\
\hline AI & 0.4918 & 0.5084 & 0.4936 & 0.5065 & 0.4951 & 0.5048 \\
\hline
\end{tabular}


Table 3: Number of results where $P_{y}=0, P_{y}$ significantly low, and $P_{y}$ significantly high for each selected LPI using a $1 \mathrm{~km}$ analysis unit.

\begin{tabular}{lrrr}
\hline Metric & $\boldsymbol{P}_{\boldsymbol{y}}=\mathbf{0}$ & Sig. Low & Sig. High \\
\hline ED & 17 & 215 & 59 \\
NPF & 333 & 0 & 33 \\
FMAX & 75 & 11 & 15 \\
PAR & 0 & 211 & 95 \\
CPAR & 6 & 296 & 110 \\
AI & 39 & 645 & 262 \\
\hline
\end{tabular}




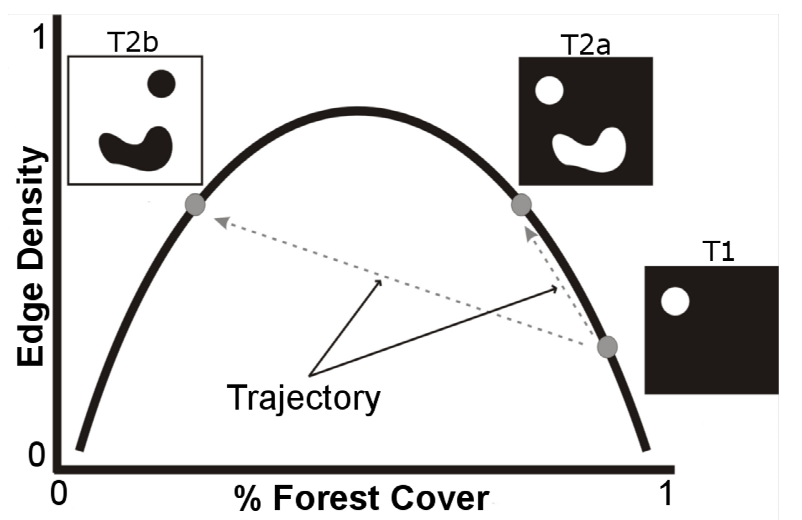

Figure 1: Hypothetical trajectory of a landscape experiencing different amounts of forest loss but with identical changes in LPI value. For interpretation consider black - forest, and white - non-forest. 

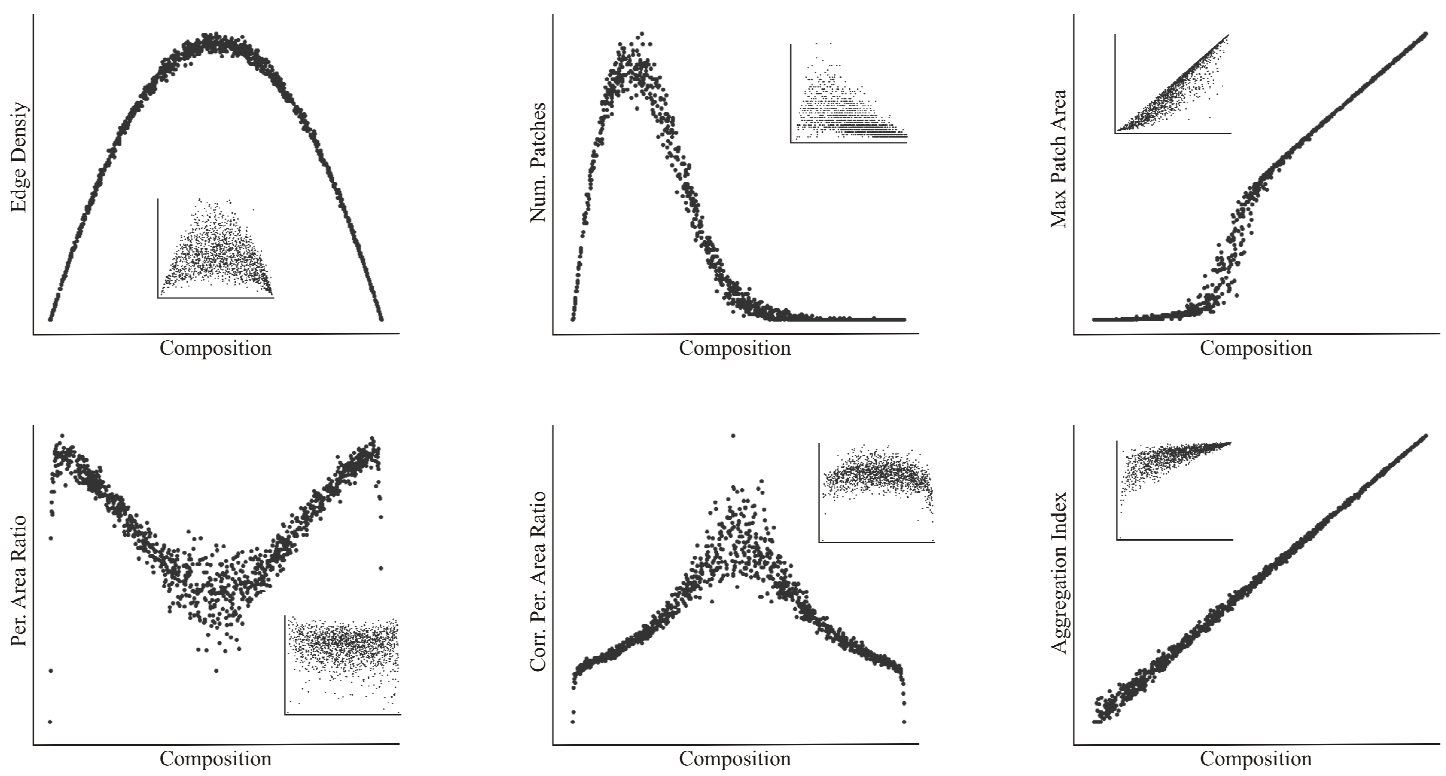

Figure 2: Relationship between landscape composition and configuration LPI for six selected metrics. Main distributions were derived from 1000 simulated binary random landscapes. Inset distributions were derived from real landscapes in our study area. 


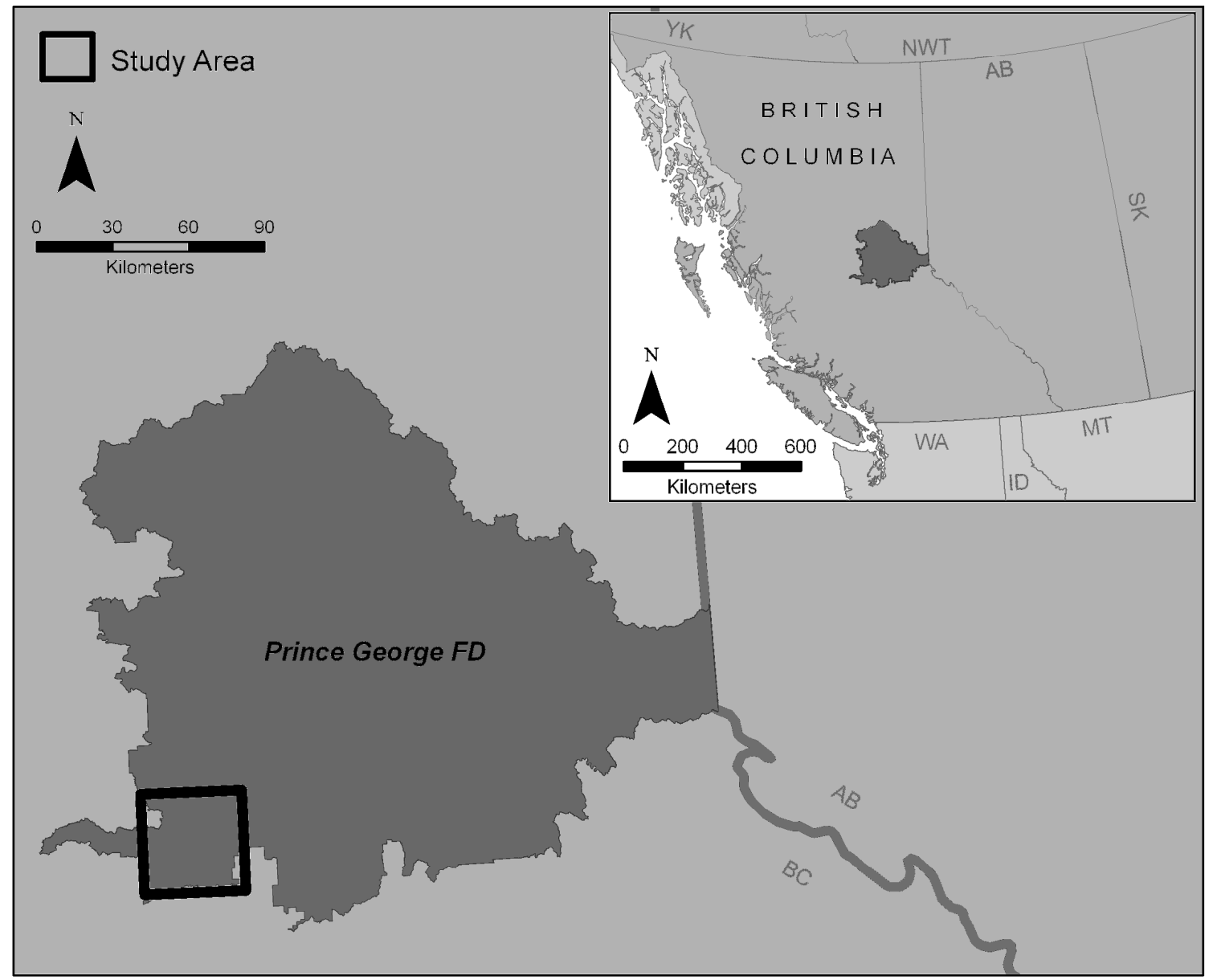

Figure 3: Study area (40 km by $40 \mathrm{~km}$ ) located within the Prince George forest district, British Columbia, Canada. 


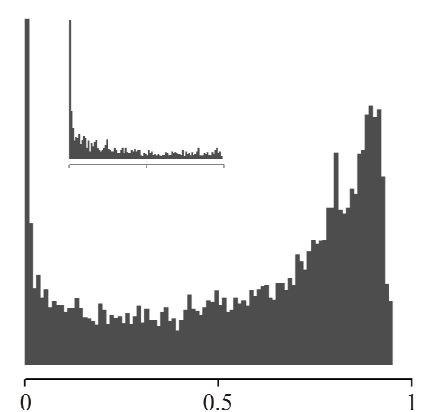

A) ED

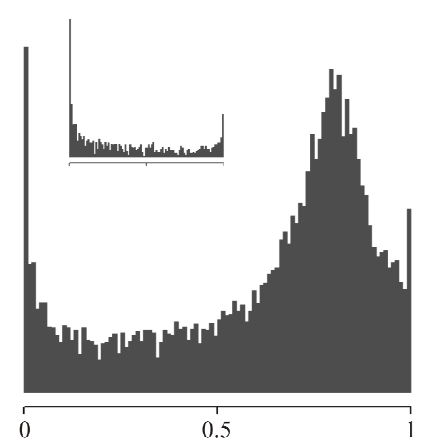

D) PAR

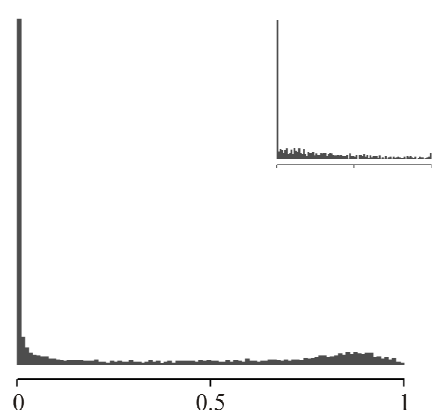

B) NPF

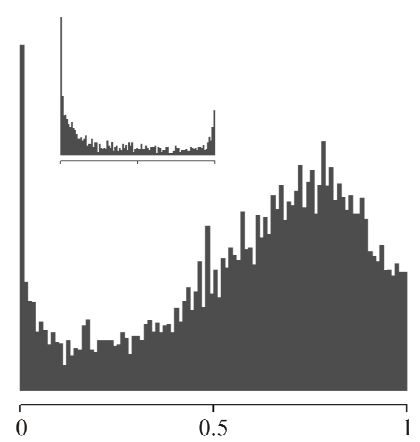

E) CPAR

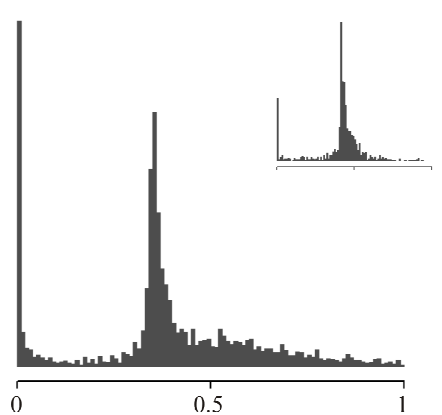

C) FMAX

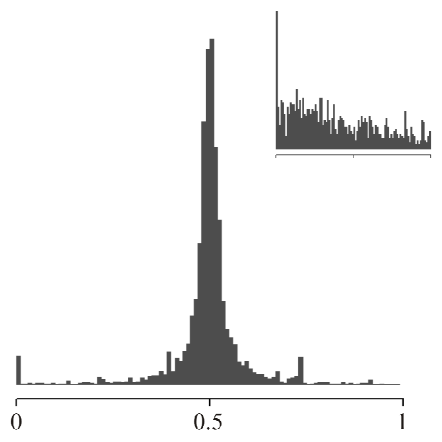

F) AI

Figure 4: Distribution of $P_{y}$ for each of the six selected LPIs using 9999 simulated binary random landscapes undergoing random change. Inset distributions are from 1231 real landscapes in our study area that have undergone change. A) edge density - ED, B) number of forest patches - NPF, C) area of largest forest patch - FMAX, D) mean landscape perimeter area ratio - PAR, E) corrected mean landscape perimeter area ratio, and $\mathrm{F}$ ) aggregation index forest class - AI. 


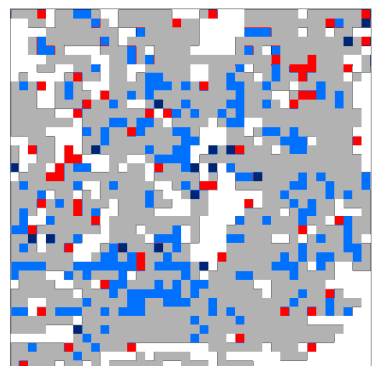

A) ED

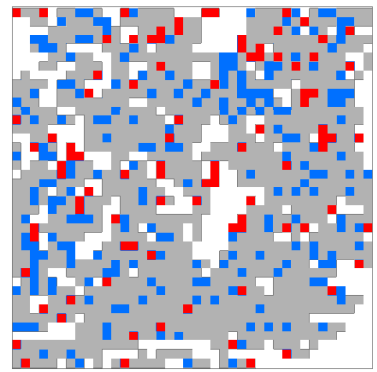

D) PAR

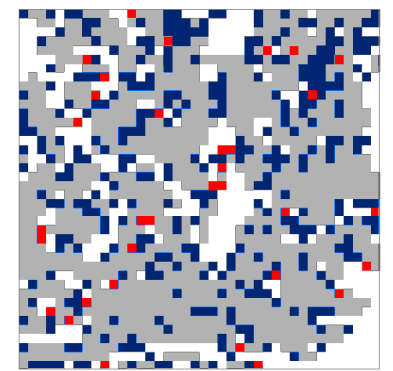

B) NPF

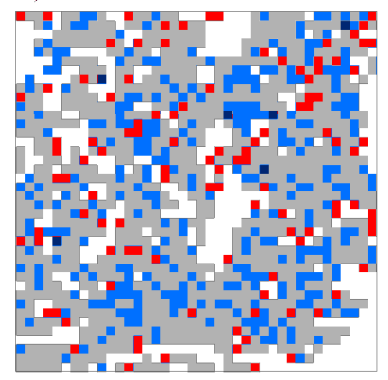

E) CPAR

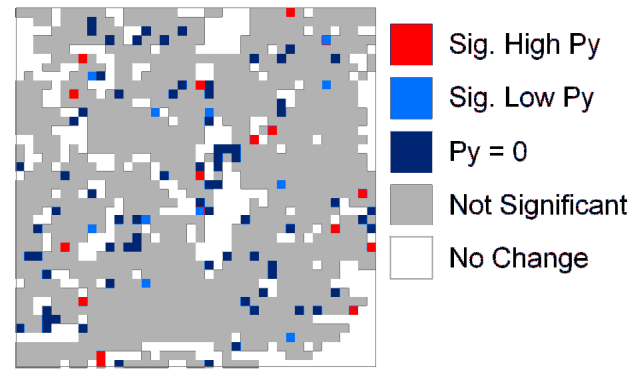

C) FMAX
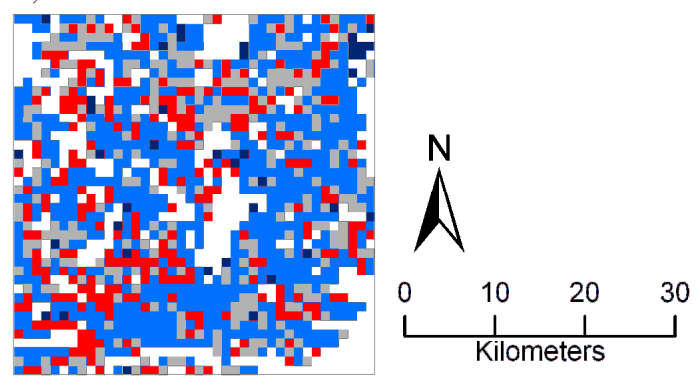

F) AI

Figure 5: Maps of significant $P_{y}$ values with $1 \mathrm{~km}$ analysis unit. Significant values were identified using simulated distribution for $P_{y}$ and $\alpha=0.10$. A) edge density - ED, B) number of forest patches - NPF, C) area of largest forest patch - FMAX, D) mean landscape perimeter area ratio - PAR, E) corrected mean landscape perimeter area ratio, and $\mathrm{F}$ ) aggregation index forest class $-\mathrm{AI}$. 


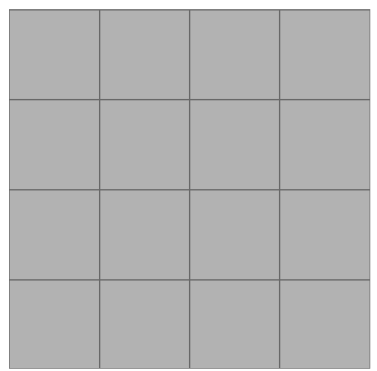

A) $\mathrm{ED}$

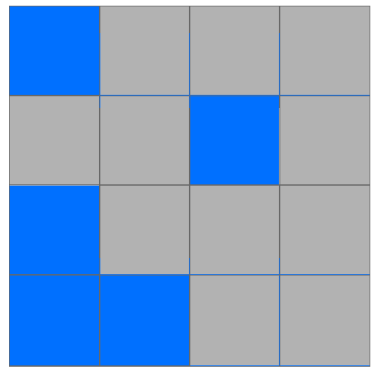

D) PAR

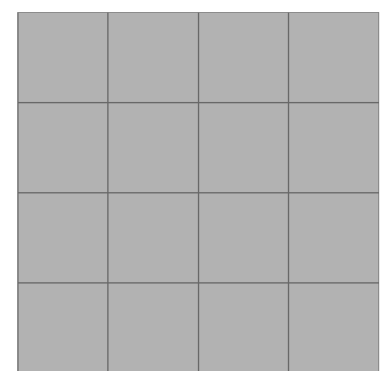

B) NPF

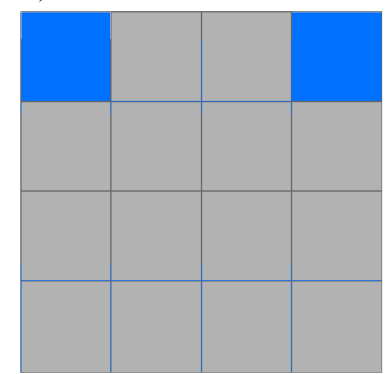

E) CPAR

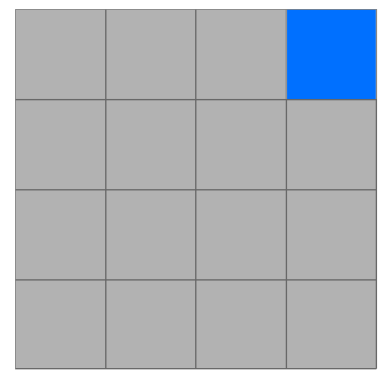

C) FMAX

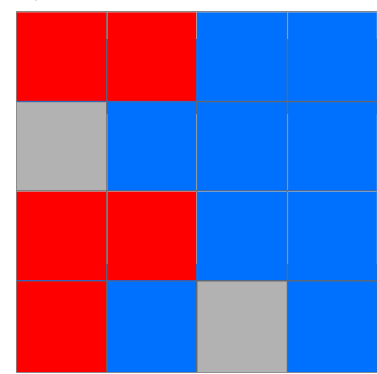

F) AI
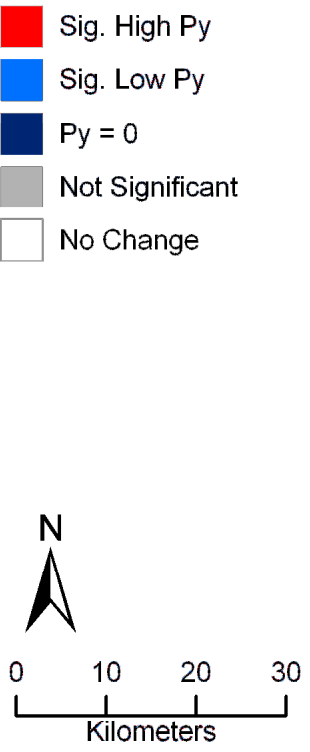

Figure 6: Maps of significant $P_{y}$ values with $10 \mathrm{~km}$ analysis unit. Significant values were identified using a simulated distribution for $P_{y}$ and $\alpha=0.10$. A) edge density - ED, B) number of forest patches - NPF, C) area of largest forest patch - FMAX, D) mean landscape perimeter area ratio - PAR, E) corrected mean landscape perimeter area ratio, and $\mathrm{F}$ ) aggregation index forest class $-\mathrm{AI}$. 


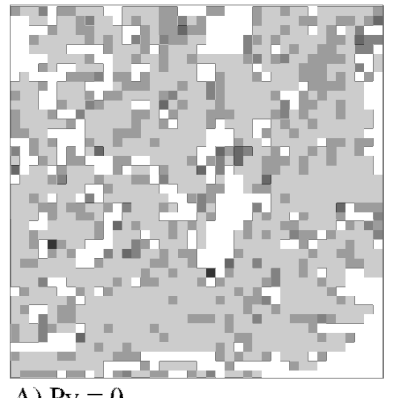

A) $\mathrm{Py}=0$

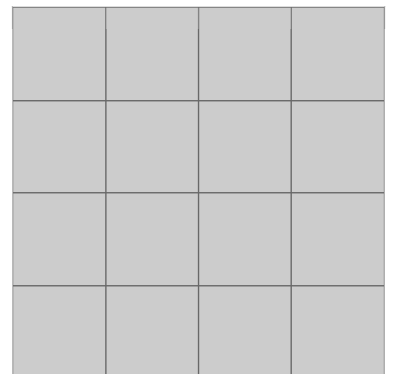

D) $\mathrm{Py}=0$

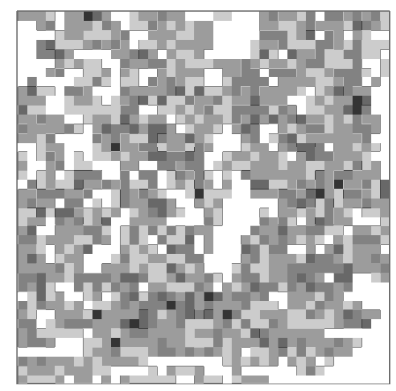

B) Sig. Low Py

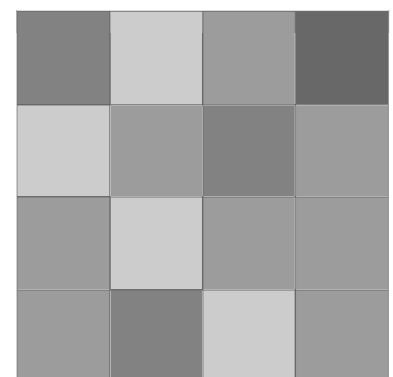

E) Sig. Low Py

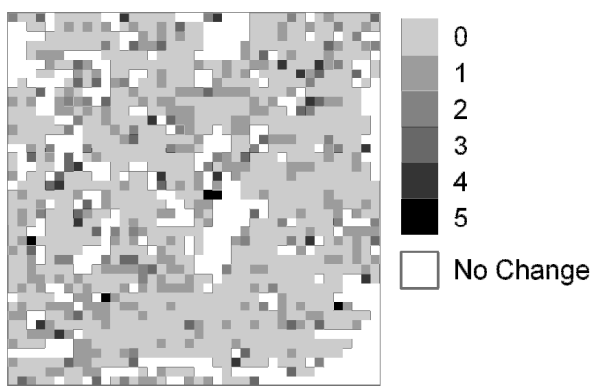

C) Sig. High Py

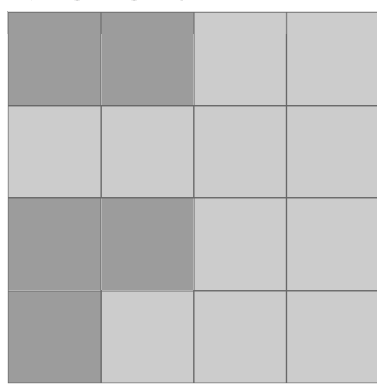

F) Sig. High Py

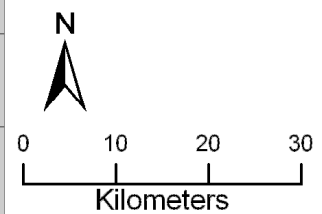

Kilometers

Figure 7: Counts of $P_{y}=0$, significantly low $P_{y}$, and significantly high $P_{y}$, for the $1 \mathrm{~km}$ (top) and $10 \mathrm{~km}$ (bottom) analysis units. A value of 0 indicates that $P_{y}$ was not significant in any of the selected LPIs, a value of 5 indicates that $P_{y}$ was significant in five of the selected LPI. There were no instances of $P_{y}$ significant for all six selected LPI. 